\title{
'Correctable undetected visual acuity deficit' in patients aged 65 and over attending an accident and emergency department
}

\author{
D Z Reinstein, N L Dorward, R P L Wormald, A Graham, I O'Connor, R M Charlton, \\ $M$ Yeatman, $R$ Dodenhoff, $R$ Touquet, $T$ Challoner
}

\begin{abstract}
The rate of occurrence of correctable undetected visual acuity deficit (CUVAD) in a population of patients aged 65 and over was investigated, using a pinhole screening method, to compare the sociodemographic and optical eye care habits of patients with or without a functionally significant CUVAD. Of 136 patients $46(34 \%)$ were found to have a functionally significant CUVAD in one or both eyes which was not significantly associated with optician or general practitioner contact, age, sex, social class, living situation, or number of medications. Half the patients with significant CUVAD had not attended for 2 years mainly because of financial considerations. Three quarters attended of their own volition; only one in seven were prompted by opticians' postal invitations. It was concluded that a significant degree of CUVAD could be detected using a simple procedure which can be carried out by general practitioners as part of their general elderly health screen.

(Brf Ophthalmol 1993; 77: 293-296)
\end{abstract}

Studies show that reduced visual acuity is one of the three major independent risk factors for accidental falls in the elderly ${ }^{1-8}$ and falls are common and expensive. ${ }^{9}$ Attention to the proper provision of corrective lenses in the elderly is therefore desirable, but currently there exists no standard way of measuring or expressing the effectiveness of optical care in the community.

In Britain, approximately nine of 10 refrac-

Institute of

Ophthalmology,

Moorfields Eye Hospital,

City Road, London

EC1V 2PD

R P L Wormald

Department of Accident and Emergency,

St Charles' Hospital,

Exmoor Street, London

W106DZ

D Z Reinstein

N L Dorward

A Graham

I O'Connor

R M Charlton

$M$ Yeatman

$R$ Dodenhoff

$R$ Touquet

T Challoner

Correspondence to:

Dr Dan Z Reinstein

Department of

Ophthalmology, Cornell

University Medical College,

1300 York Avenue New

York NY Avenue, New

Accepted for publication

27 November 1992 tions are carried out by opticians. ${ }^{10}$ Self or general practitioner referral and optician postal invitations (issued biennially to previous attenders), are the main routes by which people attend for an eye test. In 1989, eye tests for the elderly ceased to be free of charge (unless on income support or diagnosed as having diabetes mellitus, glaucoma, or a family history of glaucoma) and optician attendance rates have dropped by a third. ${ }^{11}$

Population based studies have shown that a significant proportion of impaired vision is refractive undercorrection. The Baltimore Eye Survey ${ }^{12}$ showed a rate of about one third of the general population, while a recent London inner city population survey ${ }^{13}$ showed that half of the cases of 'visual impairment' in the 65+ group (by United States criteria of a visual acuity of less than 6/12) were due to refractive undercorrection in one or both eyes. The London survey rate did not include subjects who were visually impaired in one eye alone.
Visual acuity screening by pinhole is a highly sensitive (false negative rate $1 \cdot 5 \%$ ), moderately specific (false positive rate $26 \%$ ), method for screening best visual acuity. ${ }^{14}$ No standard measure of the level of effectiveness of optical care of the population exists. We devised a means of quantifying the degree of visual acuity deficit which is correctable but undetected. The unit of this measurement is designated a 'correctable undetected visual acuity deficit' or CUVAD. It is measured in terms of the number of lines on a visual acuity chart that the patients are able to read with their present correction, subtracted from the number of lines they can read after optimum correction. CUVAD screening would provide a qualitative and quantitative measure of the level of optical correction in a population.

We investigated the occurrence rate of CUVAD in this population. This was related to the sociodemographic and optical care history for the population aged $65+$ attending a London accident and emergency department.

\section{Method}

The study was conducted in the accident and emergency department of St Charles' Hospital, London, a district of high socioeconomic deprivation. ${ }^{1516}$ Ethics committee approval was obtained beforehand and oral consent obtained from each patient. Patients were advised of any abnormality found.

Data were collected by the seven accident and emergency senior house officers (SHO) on all patients aged $65+$. Initially, patients were screened for possible cognitive impairment by the CAPE mental state test. ${ }^{17}$ Careful history was taken to obtain diagnostic category (medical surgical/minor injury and non-emergency primary care/fall/psychiatric), sociodemographic data and details regarding general practitioner and optician eye care. Patients' social class, ethnicity, marital status, home situation (independent alone/not-alone, warden controlled, part III/nursing home), social services, and medications were documented.

Patients were asked how often they attended their general practitioner and whether the general practitioner had 'ever checked their eyes or vision'; whether they had ever been to an optician and when they last attended was recorded. If more than 2 years had elapsed since their last visit they were asked why. The reason for their last attendance, what the optician had recommended, and whether they followed this were noted.

Of those who had attended at least once, 
patients were asked if they had ever received an optician's postal invitation, if they attended (or why not), what had been recommended at that visit, and whether they had followed this (or why not).

Each of the SHOs were trained and supervised in the use of the 3 metre Sonksen-Silver acuity system (Keeler) to measure CUVAD. Testing was done at a 3 metre distance (verified by a string attached to the patient), under standard lighting conditions. The optotype equivalents for this chart are: $3 / 3,3 / 4 \cdot 5,3 / 6,3 / 9,3 / 18,3 / 36$, and $3 / 60$. Visual acuity without correction and with glasses, if owned, was recorded. Visual acuity via self-held pinhole occluder was obtained. If three of five letters were read correctly, that line was considered read. CUVAD was then calculated by subtracting the chart line number readable through the pinhole from that line read with present level of correction (Fig 1). Therefore CUVAD was unobtainable in patients who normally wore glasses if they presented without their glasses.

Automated focimetry (Allergan Humphrey) was obtained on all patients' glasses to ensure that distance acuity was not being tested with reading glasses and to ascertain the level of present correction.

\section{STATISTICAL ANALYSIS}

We used the Statview 512 + statistics package for Apple Macintosh in all analyses. Contingency tables were tested using the $\chi^{2}$ statistic, except group median ages in which the Mann-Whitney $\mathrm{U}$ test was employed. Where appropriate, $\mathbf{9 5 \%}$ confidence intervals were calculated.

\section{Patients}

During the 9 week study, 277 accident and emergency attenders aged $65+$ were screened for possible inclusion in the study. Of these, 136 (half) were fully assessable. Of the patients screened there were 119 exclusions, 20 patients arrived without glasses, and two patients were registered blind. The exclusions included: too ill (22), dementia (29), mental state impaired (17), language difficulties (six), refusal (11), department too busy (28), and others (six). During the 9 week study, 473 accident and emergency attenders aged $65+$ were registered. The 196 patients not screened consisted of patients who attended at night (when there is only one doctor on duty), and those overlooked when the department was too busy (Table 1).

The group comprised 49 men and 87 women, median age 78 years (range $=65-94$ ). There was no statistically significant difference in median age (Mann-Whitney $U=21665 \cdot 5, Z=-0.93$, undetected visual acuity deficit' (CUVAD) become functionally significant (SCUVAD) when the initial best corrected visual acuity is worse than $3 / 6$.

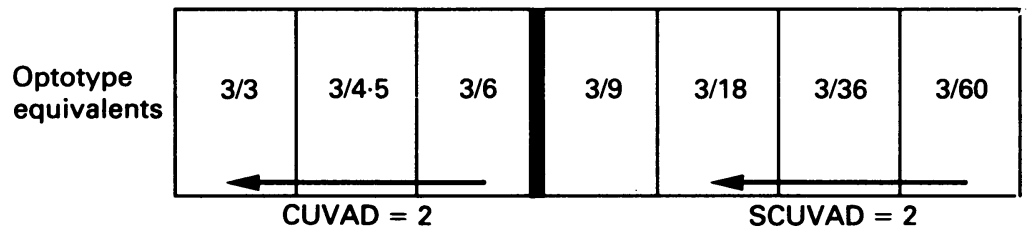

CUVAD and SCUVAD
Table 1 Age, sex, and diagnostic category distribution between study and non-study group

\begin{tabular}{|c|c|c|c|c|}
\hline & $\begin{array}{l}\text { Study } \\
\text { group } \\
(n=136)\end{array}$ & $\begin{array}{l}\text { Non-study } \\
\text { group } \\
(n=337)\end{array}$ & $\chi^{2}$ & $p$ Value \\
\hline \multicolumn{5}{|l|}{ Age } \\
\hline $\begin{array}{l}\text { Median } \\
\text { Range }\end{array}$ & $\begin{array}{l}78 \\
65-94\end{array}$ & $\begin{array}{l}76 \\
65-100\end{array}$ & & $<0.36^{\star}$ \\
\hline \multicolumn{5}{|l|}{ Sex } \\
\hline $\begin{array}{l}\text { Men } \\
\text { Women }\end{array}$ & 49 & 122 & & 0.077 \\
\hline \multicolumn{5}{|c|}{ Diagnostic category } \\
\hline $\begin{array}{l}\text { Falls } \\
\text { Medical }\end{array}$ & 41 & $\begin{array}{l}84 \\
31\end{array}$ & & \\
\hline Surgical. & 39 & 117 & & \\
\hline $\begin{array}{l}\text { Minor injury and } \\
\text { GP-type }\end{array}$ & 44 & 94 & & \\
\hline Psych & 3 & 11 & $3 \cdot 862$ & 0.425 \\
\hline
\end{tabular}

${ }^{\star}$ Mann-Whitney $U=21665 \cdot 5, Z=-0.93$

$\mathrm{p}<0.36), \operatorname{sex}\left(\chi^{2}=0.001, \mathrm{p}=0.972\right)$, or diagnostic category $\left(\chi^{2}=3.86, p=0.425\right)$ between the study group of 136 and the remainder of the 473 patients registered (Table 1 ).

\section{Results}

OCCURRENCE RATE OF CUVAD

Forty nine of $136(36 \%)$ patients were found to have a CUVAD of two lines or more in one or both eyes. By the Baltimore Eye Survey ${ }^{12}$ definition for low visual acuity of less than $20 / 40$ (equivalent to less than $3 / 6$ ), there were $46 / 136$ (34\%, 95\% confidence interval $26-42 \%$ ) patients with a functionally significant CUVAD ('SCUVAD') in one or both eyes; that is, a correctable deficit of two or more lines with present distance acuity of $3 / 9$ or worse (Fig 2). If we define SCUVAD as having this deficit in both eyes, there was an occurrence of $21 / 136(15 \cdot 4 \%$, $95 \%$ confidence interval $9 \cdot 4-21 \cdot 5 \%$ ).

There was no statistically significant difference between SCUVAD and non-SCUVAD groups with respect to age, sex, diagnostic category, social class, living situation, or number of medications (Table 2).

Among the patients presenting with a SCUVAD, a greater proportion had presented with a fall (39\% vs $31 \cdot 6 \%)$. This proportional increase, however, was not statistically significant $\left(\chi^{2}=0.709, p=0.400\right)$.

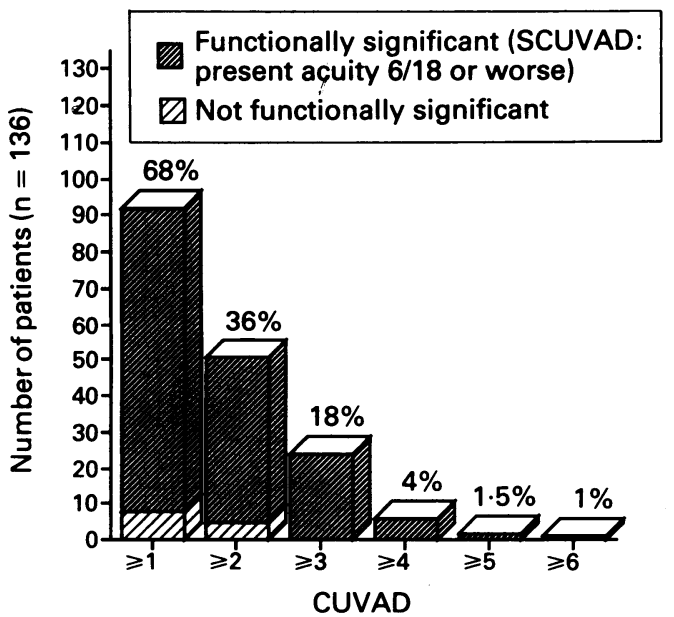

Figure 2 Correctable undetected visual acuity deficit (CUVAD) in one or both eyes. 
Table 2 Comparison of sociodemographic and primary care data between SCUVAD and non-SCUVAD groups of the study population $(n=136)$

\begin{tabular}{|c|c|c|c|c|}
\hline & $\begin{array}{l}\text { SCUVAD } \\
(n=46)\end{array}$ & $\begin{array}{l}\text { non- } \\
\text { SCUVAD } \\
(n=90)\end{array}$ & $x^{2}$ & $p$ Value \\
\hline \multicolumn{5}{|l|}{ Age } \\
\hline $\begin{array}{l}\text { Median } \\
\text { Range }\end{array}$ & 76 & 79 & & $<0.11^{\star}$ \\
\hline Sex & & & & \\
\hline $\begin{array}{l}\text { Men } \\
\text { Women }\end{array}$ & 16 & $\begin{array}{r}33 \\
57\end{array}$ & 0.169 & 0.829 \\
\hline Diagnostic category & & & 0.407 & 0.829 \\
\hline $\begin{array}{l}\text { Falls } \\
\text { Medical } \\
\text { Surgical }\end{array}$ & $\begin{array}{r}16 \\
15 \\
4\end{array}$ & $\begin{array}{r}25 \\
24 \\
5\end{array}$ & & \\
\hline Minor injury and & & & & \\
\hline $\begin{array}{l}\text { GP-type } \\
\text { Psych }\end{array}$ & $\begin{array}{r}10 \\
1\end{array}$ & $\begin{array}{r}34 \\
2\end{array}$ & $3 \cdot 745$ & 0.442 \\
\hline $\begin{array}{l}\text { Social class } \\
\text { I-II }\end{array}$ & & & & \\
\hline III & 8 & 27 & & \\
\hline $\begin{array}{l}\text { IV } \\
\text { V }\end{array}$ & 10 & $\begin{array}{l}17 \\
32\end{array}$ & $2 \cdot 804$ & 0.423 \\
\hline Living situation & & & & \\
\hline $\begin{array}{l}\text { Independent alone } \\
\text { Independent not }\end{array}$ & 25 & 46 & & \\
\hline $\begin{array}{l}\text { alone } \\
\text { Warden control/Part }\end{array}$ & 13 & 30 & & \\
\hline $\begin{array}{l}\text { III/nursing home } \\
\text { No of medications }\end{array}$ & 8 & 14 & 0.372 & 0.83 \\
\hline 0 & $\begin{array}{l}12 \\
15\end{array}$ & $\begin{array}{l}19 \\
24\end{array}$ & & \\
\hline $\begin{array}{l}2-3 \\
4-7\end{array}$ & 13 & 22 & 1.148 & $0.0 \%$ \\
\hline GP ever checked eyes? & & & 1.148 & 0.800 \\
\hline $\begin{array}{l}\text { Yes } \\
\text { No }\end{array}$ & $\begin{array}{r}5 \\
41\end{array}$ & $\begin{array}{l}12 \\
76\end{array}$ & 0.209 & 0.648 \\
\hline
\end{tabular}

$\star$ Mann-Whitney $U=1716 \cdot 5, \mathrm{Z}=-1 \cdot 163$

\section{GENERAL PRACTITIONER CONTACT}

Two of 136 patients were not general practitioner registered; $43 \%(57 / 134)$ of the patients attend their doctor at least once a month; 87\% (117/134) of patients answered that their doctor had never checked their eyes or vision. Whether their doctor had ever checked their eyes was not statistically correlated with the presence of SCUVAD (Table 2).

\section{OPTICIAN CONTACT}

One hundred and twenty eight of 136 (94\%) patients had been to the optician at least once. Of the eight that had never attended, the reasons given were 'money' (five) and 'not necessary' (three). Comparing SCUVAD and nonSCUVAD groups for those that had attended there were no statistically significant differences in time since their last visit (Table 3).

Half (21/42) the optician attenders with SCUVAD had not returned to the optician for more than 2 years. The reasons for not attending in the last 2 years were: 'money' $7 / 21$ patients,

Table 3 Optician attendance history and presence of SCUVAD

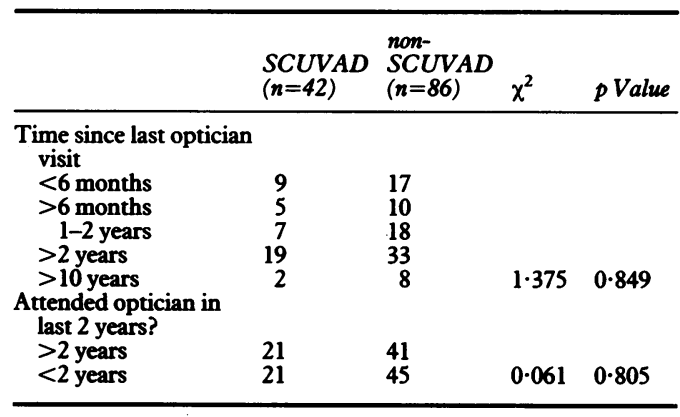

'not necessary' 11/21 patients, 'mobility' 1/21 patients, and other $2 / 21$ patients.

Reasons for the last optician attendance were: own idea: 95/128 (74\%) patients, optician postal invitation: $17 / 128(13 \%)$ patients, referred by doctor: 8/128 (6\%) patients, and other: 8/128 (6\%) patients. At that last visit, 104/128 (81\%) patients received a new prescription, five of 128 (4\%) patients were referred to hospital, and 18 (12\%) patients resulted in no prescription. Thirteen of 104 patients did not purchase the optician's prescribed glasses; 7/13 because of 'money', 4/13 because they felt it was 'not necessary', one for mobility, and one for illness related reasons.

\section{OPTICIAN FOLLOW UP}

Fifty nine of the 128 (46\%) optician attenders, answered 'yes' when asked whether they had ever received an optician postal invitation; 33 (57\%) of these did not attend following receipt of the reminder. Reasons given were: 'money' $20 / 34$ patients, 'not necessary' $10 / 34$ patients, and 'mobility' $3 / 34$ patients. Of the $26(42 \%)$ who did attend, 17/26 (65\%) patients were given a new prescription, $6 / 26(23 \%)$ patients were recommended nothing new, and one (4\%) was referred to hospital. The new glasses recommended were bought by 14/17. Of the three that did not buy the glasses recommended, two were because of 'money' and the other thought it was 'not necessary'.

\section{Discussion}

This study was carried out in an inner city accident and emergency department with a large elderly patient case load for it is in this age group that it is important to consider visual acuity deficit. ${ }^{1-8}$ People attending an inner city accident and emergency department were used as a sample of persons similar in characteristics to those that attend other primary care facilities in the inner city, in particular general practitioner practices. We felt that this sample was an appropriate model for investigation case finding for CUVAD/SCUVAD in such a population.

Bias in the CUVAD rates may be present owing to the assumption that patients with visual problems may be more accident prone; however, when separated into diagnostic categories, just under half (210/473) of the study group presented with medical or surgical problems, just under one third (138/473) as a 'minor injury and non-emergency primary care' case, and one quarter (125/473) presented with a fall (Table 1). Most 'medical' and 'surgical' problems are independent of vision, not all falls occurring in the community present to accident and emergency' and near vision deficit is more likely to be implicated in 'minor injuries'.

A number of patients with severe cognitive impairment were excluded. This could introduce bias in the rate of CUVAD, but indicates the level of CUVAD in the self-caring population living in the community - those on whom we are relying to take themselves to opticians. Patients with more mild cognitive impairment may have affected the data, but as the recall bias would be 
random in nature, it is unlikely to have affected the results in any particular direction.

We compared the age, sex, and diagnostic category of study participants with the remainder of registered accident and emergency attenders during the study period. No statistically significant differences were found in the occurrence rates of diagnostic category, age, or sex. In particular, the categories of falls or minor injuries were similar in both groups. We do not therefore believe that the patients included were biased with regard to vision.

The link between poor distance vision acuity and the increased risk of falls is now generally accepted. ${ }^{1-818}$ The question arises as to whether both eyes need to have a visual acuity deficit for the CUVAD in that patient to be functionally significant. Some authors ${ }^{18}$ suggest that stereoscopic vision is important in preventing falls. Simons et $a l^{19}$ showed that monocular impaired visual loss causes much greater loss of stereopsis than an equal degree of impairment in both eyes. Wright and Wormald ${ }^{20}$ have demonstrated a steady decrease in the degree of stereopsis with age. Perhaps it is both the loss of the binocular field and stereopsis which are important functional factors. For these reasons, we have included both those with visual impairment in one and/or both eyes when reporting the level of 'functionally significant' CUVAD in our study population as $34 \%$.

Within the SCUVAD group, there were proportionally $7 \cdot 4 \%$ more patients presenting with falls than for all other reasons together. This difference was not statistically significant, but less than one fifth of all falls may come to the immediate attention of a physician. ${ }^{8}$ This study was not intended to demonstrate again that visual acuity deficit is a risk factor for falls. Data regarding other visual causes of falls, such as restricted fields or reduced contrast sensitivity, were not collected. However, to show a difference of $10 \%(40-30 \%)$ in the fall rate between SCUVAD and non-SCUVAD groups, a study involving 800 patients would have theoretically been required.

There was no significant correlation between SCUVAD and frequency of optician attendance. Similarly, those that had not attended in the last 2 years were no more likely to have a SCUVAD. Furthermore, patients' options about their vision did not correlate with whether they required further correction; half the patients had not been to the optician in the preceding 2 years and most of these gave 'money' or 'not necessary' as their reasons.

The optician postal invitation system appears inefficient. Most patients attended the optician of their own volition and only $14 \%$ patients attended because of a postal invitation. Less than half the patients who had been to an optician claimed they had received an invitation to reattend from their optician, and more than half of these did not attend predominantly because of money or the belief that it was 'not necessary' which also embraces financial considerations (for example, 'it's not worth the difference'). It appears that the uptake rate for postal invitations from opticians would be higher if eye tests were less costly.
There emerged no particular sociodemographic profile for the patient most at risk of having a SCUVAD, so we cannot identify high risk groups that could be selected for screening.

Incorporating a simple pinhole visual acuity test into the general health screen for the elderly may prove cost effective, and this link requires further investigation. The opportunity is there: almost half the patients in our population saw their doctor at least once a month. Simple pinhole screening could lead to a reduced morbidity caused by CUVAD in the elderly.

\section{Conclusion}

There is a significant amount of CUVAD in this population. Postal invitations from opticians do not appear effective in ensuring follow up. 'Money' and 'not necessary' are the most common responses for not attending or not following opticians' recommendations. Simple pinhole screening could be carried out by general practitioners as part of their general elderly health screening to detect patients with SCUVAD. This could lead to a better level of optical correction and perhaps reduced morbidity and health costs in the elderly.

We wish to thank the accident and emergency nursing staff; the medical consultant staff at St Charles' Hospital for permission to include their patients; Allergan Humphrey Ltd for loan of focimeter, Mrs Jane Wadsworth, Department of Public Health Medicine, St Mary's Hospital Medical School for statistical advice, and Dr Gary Bell, consultant psychiatrist, $S$ Bartholomew's Hospital, Miss Claire Davies, consultant ophthalmologist, The Whittington Hospital, Miss G Vaffidis, consultan ophthalmologist, Edgware General Hospital, Dr Arv Sandana, and Dr JA Reinstein.

1 Droller H. Falls among elderly people living at home. Geriatrics 1955; 10: $239-44$

2 Brocklehurst JC, Exton-Smith AN, Lempert Barber SM, Hunt LP, Palmer MK. Fracture of the femur in old age: a two-centre study of associated clinical factors and the cause of the fall. Age Ageing 1978; 7: 7-15.

3 Felson DT, Anderson JJ, Hannan MT, Milton RC, Wilson PWF, Kiel DP. Impaired vision and hip fracture, the Framingham study. F Am Geriatr Soc 1989; 37: 495-500.

4 Prudham D. Factors associated with falls in the elderly: a community study. Age Ageing 1981; 10: 141-6.

5 Tinetti ME, Williams TF, Mayewski R. Fall risk index for elderly patients based on number of chronic disabilities. Am $\mathcal{F}$ Med 1986; 80: 429-434.

6 Tinetti ME, Speechley M, Ginter SF. Risk factors among elderly persons living in the community $N E$ Engl f Med 1988; 319: 1701-7.

7 Perry BC. Falls among the elderly living in high-rise apartments. F Fam Pract 1982; 14: 1069-73.

8 Grisso JA, Kelsey JL, Strom BL, Chiu GY, Maislin G, O'Brien LA, et al. Risk factors for falls as a cause of hip fracture in women. N Engl f Med 1991; 324: 1326-31.

9 Gryfe CI, Amies A, Ashley MJ. A longitudinal study of falls in an elderly population: I. Incidence and morbidity. $A g e$ Ageing 1977; 6: 201-10.

10 Anonymous. GOS sight tests down on year to March 31. Optician 1991; Sep 6: 5.

11 Rosenthal RA. High street eye tests. BMf 1990; 300: 695-6.

12 Tielsch JM, Sommer A, Witt K, Katz J, Royall RM. Blindness and visual impairment in an American urban population. The Baltimore eye survey. Arch Ophthalmol 1990; 108: 286 90.

13 Wormald RPL, Wright LA, Courtney P, Beaumont B, Haines AP. Visual problems in the elderly population and implications for services. BMF 1992; 304: 1226-9.

14 Lowenstein JL, Palmberg PF, Connett JE, Wentworth DN. Effectiveness of a pinhole method for visual acuity screening. Arch Ophthalmol 1985; 103: 222-3.

15 Jarman B. Identification of underprivileged areas. BMF 1983; 286: 1705-9.

16 Jarman B. Underprivileged areas: validation and distribution of scores. $B M \mathcal{F} 1984 ; 289$ : 1587-92.

17 Pattie AH. A survey version of the Clifton assessment procedures for the elderly (CAPE). Br $\mathcal{F}$ Soc Clin Psychol 1981; 20: 173-8.

18 Cohn TE, Lasley DJ, Perry BC. Falls among the elderly: a review of the methods and conclusions of epidemiologic studies. Clin Geriatr Med 1985; 1: 601.

19 Simons K. Effects of steropsis of monocular versus binocular degradation of image contrasts. Invest Ophthalmol Vis $\mathrm{Sci}$ 1984; 25 : 987-9.

20 Wright LA, Wormald RPL. Stereopsis and aging. Eye 1992; 6 : 473-6. 